\title{
A Technique for Screening Grape Germplasm for Resistance to Meloidogyne incognita
}

\author{
P. M. Cousins, USDA-ARS, Plant Genetic Resources Unit, New York State Agricultural Experiment Station, Cor- \\ nell University, Geneva 14456; and M. A. Walker, Department of Viticulture and Enology, University of California, \\ Davis 95616
}

\begin{abstract}
Cousins, P. M., and Walker, M. A. 2001. A technique for screening grape germplasm for resistance to Meloidogyne incognita. Plant Dis. 85:1052-1054.

A technique to evaluate the root-knot nematode resistance of grape seedlings was developed. Seedlings of rootstock crosses and nematode-susceptible Vitis vinifera cvs. Colombard and Carignane were inoculated with Meloidogyne incognita juveniles. Reproduction of nematodes on individual plants was measured by counting the number of egg masses stained with eosin and the number of eggs present. Egg mass counts were highly correlated with egg counts. Resistant and susceptible cultivars could be clearly distinguished by the number of egg masses produced on vegetatively propagated cuttings. It is concluded that egg mass counting can substitute for the more laborious and time-consuming methods of counting nematode eggs or juveniles in the evaluation of root-knot nematode resistance in Vitis.
\end{abstract}

Additional keywords: resistance screening, rootstock breeding

Grape rootstocks resistant to root-knot nematodes (Meloidogyne spp.) with improved horticultural characteristics are one goal of breeding programs (14). However, traditional methods for screening seedlings have large requirements for time and space. Some established grape screening techniques measure pathological symptoms but do not measure resistance per se, which generally is defined as the reduced reproduction of the nematode on the host plant relative to a susceptible control (12).

Vegetatively propagated cuttings have formed the basis of standard nematode resistance evaluations in grape. Plants of cultivars and accessions to be tested are grown in the field, then propagated as cuttings and grown until ready for inoculation $(2,4,9,15)$. Time elapsed from inoculation until screening varies widely, from 3 weeks (4) to 4 months (15). Different forms of inocula have been used, including secondstage juveniles (J2) (15), eggs (2), or chopped nematode-infected tomato roots (9). Resistance determination typically involves equipment- and time-intensive methods such as extraction of nematode juveniles from soil and plant roots $(2,15)$

Corresponding author: M. A. Walker

E-mail: awalker@ucdavis.edu

Accepted for publication 11 June 2001.

Publication no. D-2001-0717-01R

(C) 2001 The American Phytopathological Society or extraction of eggs from roots (2). Screening techniques that only evaluate root galling $(4,9)$ do not directly measure nematode reproduction.

In tomato, peanut, bean, and maize, counting stained egg masses has been used effectively in screening plant material for root-knot nematode resistance $(3,6,7,10,11)$. Counting stained egg masses is particularly useful when screening plants that produce small or few galls in response to nematodes and where the correlation between galling and nematode reproduction is low. High levels of reproduction of the rootknot nematode Meloidogyne nataliei Golden, Rose, \& Bird were detected on Concord grape roots from a declining vineyard, yet no galling was apparent (5). Egg masses were visible on these ungalled roots, suggesting that egg masses are a more reliable measure of root-knot nematode reproduction on grape than is galling.

Improvements in nematode resistance screening techniques would benefit grape breeding programs. In particular, modifications are needed to allow the screening of seedlings for resistance, measure nematode reproduction (resistance) rather than galling, and accelerate the testing of cuttings. Our objective was to develop and validate a new technique for evaluating grape seedlings and cuttings, utilizing egg mass staining to measure root-knot nematode resistance.

\section{MATERIALS AND METHODS}

Inoculum. Meloidogyne incognita (Kofoid \& White) Chitwood race 3 was main- tained on tomato (Lycopersicon esculentum Mill.) cvs. Tropic and Rutgers in greenhouse pot culture. This nematode reacts as expected with known susceptible (Vitis vinifera L. cvs. Colombard and Cabernet Sauvignon) and resistant (Vitis hybrid cv. Harmony) grape cultivars and has been used in other studies of grape nematode resistance (15). Nematode stock cultures on tomato were inoculated with eggs extracted with a dilute bleach solution (8). Second-stage juveniles (J2) were collected for inoculation onto grape by placing 3 - to 5 -cm-long infected tomato root pieces (8 weeks after inoculation) into a mist chamber extraction system (1) and collecting hatched juveniles after 3 to 5 days. Inoculum concentration was evaluated by counting $\mathrm{J} 2$ nematodes present in a $10-\mathrm{ml}$ sample taken following agitation. Grape test plants were inoculated with 1,500 J2 each. Inoculum was dispensed into a $0.5 \mathrm{~cm}$ wide $\times 2$ to $3 \mathrm{~cm}$ deep hole approximately $1 \mathrm{~cm}$ from the crown of the plant, which was closed after inoculation.

Seedling plant study-host plant material. Seedlings of two open-pollinated $V$. vinifera wine grape cultivars, Colombard and Carignane, and five F1 crosses of grape rootstock cultivars were tested. The rootstock crosses were Ramsey $\times$ St. George, Dog Ridge $\times$ 3309C, Harmony $\times$ 3309C, 1613C $\times$ Riparia Gloire, and 161$49 \mathrm{C} \times$ St. George. The susceptibility of open-pollinated seedlings of Colombard and Carignane had been established in previous studies (data not shown), so these seedlings were used as susceptible controls in this experiment. All seeds were coldtreated for 3 months at $4^{\circ} \mathrm{C}$. V. vinifera seeds were cleaned, then planted at six seeds per pot. Once cotyledons were extended, seedlings were thinned to one per pot. Seeds of rootstock crosses were bathed for $24 \mathrm{~h}$ in $37^{\circ} \mathrm{C} \mathrm{H}_{2} \mathrm{O}$, then washed, rinsed, and placed on moist tissue paper in plastic culture dishes. Culture dishes were held in the dark in a greenhouse. As seeds germinated, they were transferred to individual pots. Flats of pots containing sprouted, transplanted seedlings were covered with moist newspaper until cotyledons emerged. All seedlings were grown in a mixture of steam-sterilized soil, fir bark, and sand mix (10\% sandy clay loam, $25 \%$ fir bark, $65 \%$ 
sand by volume) in 6-cm-square plastic pots. Seedlings were maintained in a greenhouse with a temperature range of 20 to $30^{\circ} \mathrm{C}$. From 30 to 60 seedlings were inoculated per population. Plants were inoculated as soon as they had two true leaves (approximately 1 month after plating for rootstock crosses or planting for $V$. vinifera seedlings).

Seedling plant study-evaluation. Nematode reproduction was assessed 6 weeks after inoculation. Once soil was washed from the roots, the entire root system was immersed in $0.25 \mathrm{~g} /$ liter $\mathrm{H}_{2} \mathrm{O}$ eosin-Y (Sigma 6003) for $1 \mathrm{~h}$, then rinsed to remove excess stain (3). Stained roots were blotted dry, weighed, and cut into 3to $5-\mathrm{cm}$ pieces. All stained egg masses were counted. Eggs were extracted with $\mathrm{NaOCl}$ as a $10 \%$ by volume commercial bleach solution $(5.25 \% \mathrm{NaOCl}$ by weight) (8). All the roots of each seedling were immersed in $200 \mathrm{ml}$ of bleach solution and stirred for 3 min with a glass rod. Following agitation, the solution was poured over a 200 mesh sieve (pore size $=75 \mu \mathrm{m}$ ) to remove root pieces, then the extraction vessel, roots, and sieve were rinsed with approximately $100 \mathrm{ml}$ of water to free residual eggs. Eggs in a $10-\mathrm{ml}$ sample of the egg suspension were counted, and the total volume of egg suspension was measured to estimate the total eggs for each plant. Egg masses and eggs were counted on at least 21 plants per population (Table $1)$.

Cutting grown plant study-host material. Green cuttings of Colombard and Harmony were taken from mother plants growing in a greenhouse. Cuttings were placed in ground bark propagation sponges (GrowTech Techniculture, Hollister, CA) in a bottom-heated mist bed (approximately $30^{\circ} \mathrm{C}$ ). Within 3 weeks, the cuttings had rooted well enough for potting. Plants were potted with the same pots and soil as described above. Plants were inoculated when the roots began to emerge from the bottom of the pots, about 9 days after potting. Twenty-three Colombard and 10 Harmony cuttings were inoculated.

Cutting-grown plant study-evaluation. Six weeks after inoculation, soil was washed from the roots of inoculated plants. Roots were stained in eosin- $\mathrm{Y}$ as above, and egg masses were counted on $19 \mathrm{Co}$ lombard and 9 Harmony plants. The remaining plants were destructively sampled or used for photographic documentation, and egg masses on these plants were not counted.

Egg mass counts were regressed separately against eggs per plant and root weight. Eggs per plant was regressed against root weight (Table 1). The first 20 plants per population with egg masses visible or eggs present were used in each regression analysis. The total number of plants screened per population varied due to differences in the nematode resistance of each cross. Plants with neither egg masses nor eggs present were not included in the regression analysis of egg masses and eggs per plant (Table 1). Correlation of egg mass counts and eggs per plant with root weights were calculated using all plants screened.

\section{RESULTS}

Egg mass counts were highly correlated with eggs per plant $(r=0.96, \mathrm{df}=138$ for all plants bulked). Most individual seedling populations showed a similarly high correlation between numbers of egg masses and numbers of eggs per plant. However, the seedlings of the cross Harmony $\times$ 3309C exhibited a relatively low correlation between egg masses and eggs per plant $(r=$ 0.52 , df $=18$ ). This may have been attributable to the low numbers of egg masses found on seedlings of this cross.

Root weights were not closely correlated with egg mass counts $(r=-0.06, \mathrm{df}=217)$ or with eggs per plant $(r=-0.06$, df $=$ 217), although certain populations had higher correlations between root weights and nematode reproduction than others (Table 1). The highest correlations between nematode reproduction (egg masses or eggs) and root weight were found in the $V$. vinifera seedling populations.

For cutting-grown plants, a $t$ test was used to determine if there was any difference between the average number of egg masses exhibited by the two cultivars. The two cultivars had different average num- bers of egg masses $(P=0.001)$. None of the nine Harmony plants had egg masses, while nematode egg masses on Colombard cuttings ranged from 78 to 222 (data not shown).

\section{DISCUSSION}

Egg mass counts for evaluating grape root-knot nematode resistance correlate very well with egg counts and can substitute for more laborious evaluation methods. Egg masses are easily stained and counted with the unaided eye, while extraction and identification of $\mathrm{J} 2$ and eggs requires more training and microscopes. Using galling as a measure of grape nematode resistance $(4,9)$ can be hampered by minimal or uneven galling. Some root-knot nematodes can reproduce on grape without galling (5), and a resistance screen based on galling could misclassify ungalled plants as resistant despite high levels of reproduction. Work in peanut and cotton has also shown that differences in galling are not necessarily reflective of differences in nematode reproduction $(6,13)$.

The screening technique described here is faster than other methods for measuring root-knot nematode resistance in grape. However, it is unlikely within the short time between inoculation and screening that differences in plant growth or size attributable to differential response to nematodes will be seen. Indeed, in both $V$. vinifera seedling populations that we tested, individual seedlings with heavier roots generally had more total egg masses and eggs. Reduction in growth of $V$. vinifera with increasing numbers of root-knot nematodes has been observed (2), but that study involved much larger initial inoculum levels and a longer period between inoculation and evaluation than this study.

The technique demonstrated here evaluates smaller, younger plants than previous techniques. Previous evaluations of grape germplasm for nematode resistance were on cuttings from field-grown plants $(3,4,9,15)$ or seedlings grown in flats $(9)$. Seedlings of grape rootstock crosses may require several years of growth in the vineyard before they are large enough to provide sufficient material for cuttings.

Table 1. Correlation of root-knot nematode reproduction and root weight from grape seedling populations

\begin{tabular}{|c|c|c|c|c|c|}
\hline \multirow[b]{2}{*}{ F1 population or cultivar } & \multirow[b]{2}{*}{$\begin{array}{c}\text { Plants } \\
\text { screened }\end{array}$} & \multirow[b]{2}{*}{$\begin{array}{l}\text { Plants with egg } \\
\text { masses or eggs }\end{array}$} & \multicolumn{3}{|c|}{ Correlation coefficient } \\
\hline & & & $\begin{array}{c}\text { Egg masses } \times \text { eggs in first } \\
20 \text { plants with eggs or egg } \\
\text { masses }(n=20)\end{array}$ & $\begin{array}{l}\text { Eggs } \times \text { root weight in } \\
\text { all plants screened }\end{array}$ & $\begin{array}{l}\text { Egg masses } \times \text { root weight } \\
\text { in all plants screened }\end{array}$ \\
\hline Ramsey $\times$ St. George & 26 & 25 & 0.95 & 0.13 & 0.15 \\
\hline Dog Ridge $\times 3309 \mathrm{C}$ & 33 & 23 & 0.99 & -0.12 & -0.09 \\
\hline Harmony × 3309C & 52 & 22 & 0.52 & -0.03 & -0.02 \\
\hline 1613C $\times$ Riparia Gloire & 39 & 27 & 0.94 & 0.17 & 0.19 \\
\hline $161-49 \mathrm{C} \times$ St. George & 25 & 23 & 0.93 & 0.14 & 0.18 \\
\hline $\begin{array}{l}\text { cv. Carignane } \\
\text { (open-pollinated) }\end{array}$ & 21 & 21 & 0.97 & 0.41 & 0.30 \\
\hline $\begin{array}{l}\text { cv. Colombard } \\
\text { (open-pollinated) }\end{array}$ & 23 & 21 & 0.95 & 0.63 & 0.67 \\
\hline Pooled data & 219 & 162 & 0.96 & -0.06 & -0.06 \\
\hline
\end{tabular}


Evaluation prior to field planting accelerates the breeding cycle by allowing selection of resistant plants soon after germination, and reduces demands on vineyard space.

The use of egg mass staining to assess nematode reproduction on grape roots is adaptable to cuttings. The cultivar Harmony, known to resist the nematodes used in this study, and Colombard, known to be susceptible to this root-knot nematode population, were clearly separated in this study. In fact, no nematode reproduction was observed on Harmony, while nematode reproduction on Colombard was high. Our technique for testing cuttings has since been adopted for use in screening candidate rootstock germplasm and evaluating rootstocks for nematode resistance (M. A. Walker, personal communication).

In contrast to other studies in which nematodes were permitted to feed for up to 4 months, our protocol requires only 6 weeks from inoculation to screening. When using our technique, time from propagation (planting or plating) to inoculation is typically 4 weeks for seedling screening and can be as short as 3 weeks for cuttings under optimal conditions. Although the seedling root system is destroyed in evaluation, green cuttings made from the shoot at screening time have been found to root readily under mist propagation.

\section{ACKNOWLEDGMENTS}

We are grateful for research support provided by the California Grape Rootstock Improvement Commission and the California Table Grape Commission. We also acknowledge the fellowship support of the American Society for Enology and Viticulture and the American Wine Society Educational Foundation.

\section{LITERATURE CITED}

1. Barker, K. R. 1985. Nematode extraction and bioassays. Pages 19-35 in: An Advanced Treatise on Meloidogyne. Vol. 2. Methodology. K. R. Barker, C. C. Carter, and J. N. Sasser, eds. North Carolina State University Graphics, Raleigh.

2. Bloodworth, P. J., Nesbitt, W. B., and Barker, K. R. 1980. Resistance to root-knot nematodes in Euvitis $\times$ Muscadinia hybrids. Pages 275-292 in: Proc. Int. Sympos. Grape Breed., 3rd.

3. Castagnone-Sereno, P., Wajnberg, E., Bongiovanni, M., Leroy, F., and Dalmasso, A. 1994. Genetic variation in Meloidogyne incognita virulence against the tomato $\mathrm{Mi}$ resistance gene: Evidence from isofemale line selection studies. Theor. Appl. Genet. 88:749-753.

4. Firoozabady, E., and Olmo, H. P. 1982. The heritability of resistance to root-knot nematode (Meloidogyne incognita acrita CHIT.) in Vitis vinifera $\times$ V. rotundifolia hybrid derivatives. Vitis 21:136-144.

5. Golden, A. M., Rose, L. M., and Bird, G. W. 1981. Description of Meloidogyne nataliei $\mathrm{n}$. sp. (Nematoda: Meloidogynidae) from grape (Vitis labrusca) in Michigan, with SEM observations. J. Nematol. 13:393-400.

6. Holbrook, C. C., Knauft, D. A., and Dickson, D. W. 1983. A technique for screening peanut for resistance to Meloidogyne arenaria. Plant Dis. 67:957-958.
7. Holbrook, C. C., Noe, J. P., Gorbet, D. W., and Stephenson, M. G. 1998. Evaluation of peanut breeding lines with resistance to the peanut root-knot nematode. Crop Sci. 38:260262.

8. Hussey, R. S., and Barker, K. R. 1973. A comparison of methods of collecting inocula of Meloidogyne spp., including a new technique. Plant Dis. Rep. 57:1025-1028.

9. Lider, L. A. 1954. Inheritance of resistance to a root-knot nematode (Meloidogyne incognita var acrita Chitwood) in Vitis spp. Proc. Helminth. Soc. Wash. 21:53-60.

10. Omwega, C. O., Thomason, I. J., and Roberts, P. A. 1988. A nondestructive technique for screening bean germ plasm for resistance to Meloidogyne incognita. Plant Dis. 72:970-972.

11. Poerba, Y. S., Windham, G. L., and Williams, W. P. 1990. Resistance of maize hybrids to Meloidogyne javanica. Nematropica 20:169172.

12. Roberts, P. A. 1990. Resistance to nematodes: Definitions, concepts, and consequences. Pages 1-15 in: Methods for Evaluating Plant Species for Resistance to Plant-Parasitic Nematodes. J. L. Starr, ed. Society of Nematologists, Hyattsville, MD.

13. Shepherd, R. L. 1979. A quantitative technique for evaluating cotton for root-knot nematode resistance. Phytopathology 69:427-430.

14. Walker, M. A. 1992. Future directions for rootstock breeding. Pages 60-66 in:. Proceedings Rootstock Seminar: A Worldwide Perspective. J. A. Wolpert, M. A. Walker, and E. Weber, eds. Reno, Nevada, June 24, 1992. American Society for Enology and Viticulture, Davis, CA.

15. Walker, M. A., Ferris, H., and Eyre, M. 1994. Resistance in Vitis and Muscadinia species to Meloidogyne incognita. Plant Dis. 78:1055-1058. 